Int. J. Electrochem. Sci., 15 (2020) $3204-3218$

\title{
A Facile Strategy for Electrochemical Analysis of Chrysophanol Based on Nitrogen-Doped Graphene Supported ZnO Nanorods/Au Multihybrid Nanoarchitecture
}

\author{
Ling Shi ${ }^{1,2}$, Zefeng Wang ${ }^{1,2, *}, \mathrm{Na} \mathrm{Wu}^{1,2}$, Xianlan Chen ${ }^{1,2}$, Guangming Yang ${ }^{1,2, *}$, Wei Liu $^{1,2, *}$ \\ ${ }^{1}$ School of science, Honghe University, mengzi, Yunnan 661199, PR China \\ ${ }^{2}$ Key Laboratory of Natural Pharmaceutical \& Chemical Biology of Yunnan Province, Mengzi, \\ Yunnan 661199, PR China \\ *E-mail: wangzefeng841006@ 163.com, yangguangmingbs@126.com, liuwei4728@126.com
}

doi: $10.20964 / 2020.04 .43$

Received: 13 December 2019 / Accepted: 4 February 2020 / Published: 10 March 2020

For the first time, $\mathrm{N}$-doped reduced graphene oxide supported $\mathrm{ZnO}$ nanorods loading $\mathrm{Au}$ nanoparticles (N-rGO-ZnO-Au) multihybrid nanoarchitecture are successfully achieved via a simple strategy. N-rGO served as a large support material can disperse $\mathrm{ZnO}$ nanorods, and the abundant active sites of $\mathrm{ZnO}$ are benefit for growing $\mathrm{Au}$ NPs. The obtained mutihybrid nanoarchitectured materials are clearly characterized by transmission electron microscopy (TEM), X-ray photoelectron spectroscopy (XPS) and X-ray diffraction (XRD). The electrochemical behaviors and reaction mechanism of fabricating sensor toward chrysophanol (CHR) are investigated. The fabricated electrochemical sensor possesses excellent electrochemical characteristics for detecting of CHR. The peak current is proportional to CHR concentration in the range from 1.57 to $27.53 \mu \mathrm{M}$, the detection limit is $0.49 \mu \mathrm{M}$. Moreover, the suggested electrochemical sensor also show good reproducibility, stability and selectivity, and has been used to detect CHR in real sample.

Keywords: Gold nanoparticles; $\mathrm{ZnO}$ nanorods; N-doped reduced graphene oxide; electrochemical sensor; chrysophanol

\section{$\underline{\text { FULL TEXT }}$}

(C) 2020 The Authors. Published by ESG (www.electrochemsci.org). This article is an open access article distributed under the terms and conditions of the Creative Commons Attribution license (http://creativecommons.org/licenses/by/4.0/). 